\title{
RELATO DE EXPERIÊNCIA: ESTÁGIO DE DOUTORADO NO EXTERIOR
}

Luciana de Mesquita Silva é professora de Português e Inglês no CEFET/RJ (Campus Petrópolis) e doutoranda em Estudos da Linguagem na PUC-Rio.

E-mail: luciana.cefetrj@gmail.com

\section{Resumo}

O objetivo deste artigo é descrever meu estágio de doutorado desenvolvido na University of Massachusetts Amherst, de setembro a dezembro de 2013, sob a orientação do Prof. Dr. Edwin Genztler.

\begin{abstract}
The aim of this article is to describe my PHD research proposal developed at the University of Massachusetts Amherst, from September to December 2013, under the supervision of Dr. Edwin Gentzler.
\end{abstract}

\section{1) Introdução}

Minha pesquisa no âmbito do programa de Doutorado em Estudos da Linguagem na PUC-Rio tem como foco a recepção das obras Beloved e Jazz, da escritora estadunidense Toni Morrison, no Brasil, através de suas traduções. Nesse sentido, a escolha da University of Massachusetts Amherst para a realização de parte desse estudo, com bolsa CAPES/PDSE, não foi aleatória. Trata-se de uma universidade de relevância para os Estudos da Tradução: seu programa de mestrado é considerado um dos mais conceituados nos Estados Unidos, seu centro de tradução é uma empresa consolidada que oferece serviços de tradução em mais de oitenta línguas, aliando o universo acadêmico ao mercado de trabalho, e seu corpo docente é formado por estudiosos renomados, tais como Edwin Gentzler, meu co-orientador, e Maria Tymoczko.

De acordo com o meu plano de pesquisa no exterior, o estágio na University of Massachusetts Amherst teria como objetivos fundamentais a ampliação dos estudos teóricos sobre tradução e uma compreensão mais abrangente sobre o posicionamento de Morrison e de seus romances nos contextos da literatura afro-americana e do campo literário estadunidense como um todo. Para tanto, as atividades realizadas nesse período visaram a contribuir para essa proposta por meio da participação em cursos, do acesso ao centro de tradução, da visita à biblioteca, da participação em eventos, dos encontros com acadêmicos, dos contatos relativos a Morrison, entre outras. Tais atividades serão descritas nas seções a seguir.

\section{2) Atividades realizadas}

\section{1) Participação em cursos}

$\mathrm{Na}$ University of Massachusetts Amherst, tive a oportunidade de participar de três cursos, os quais foram muito importantes para a minha pesquisa: "Introdução ao Inglês Afro-Americano" (Lisa Green); "Tradução, Globalização e Tecnologia" (Edwin Gentzler) e "Teoria e Prática de Tradução" (Maria Tymoczko).

O propósito da disciplina "Introdução ao Inglês Afro-Americano" foi o de apresentar o inglês afro-americano $(A A E)$, discutir alguns de seus aspectos e promover reflexões sobre o seu uso em diferentes situações. Em sua primeira parte, foram abordados os componentes gramaticais - sintaxe, semântica e fonologia - e lexicais, focalizando-se o contraste do $A A E$ com outras variantes da língua inglesa. Já na segunda 
parte, a presença do $A A E$ em diversos contextos, tais como a literatura, o cinema e a música, foi o tópico discutido.

Durante suas aulas, Green fez referência a determinadas peculiaridades do $A A E$ e abriu discussões sobre o uso de tal dialeto como um instrumento para a construção de identidade, não só por uma parcela da comunidade negra estadunidense, como também por aqueles que, de alguma forma, teriam como objetivo se aproximarem do universo afro-americano através da linguagem. Esse curso contribuiu bastante para o meu entendimento do $A A E$ como uma variedade autêntica, representada de formas distintas, em cenários variados. A partir dele, comecei a levantar questionamentos com relação ao meu próprio estudo: Como são as representações do $A A E$ nas obras de Morrison? $\mathrm{O}$ que a presença ou a ausência do $A A E$ em certo contexto pode sugerir? Os regionalismos são levados em consideração? Dessa forma, passei a ter uma maior consciência sobre as generalizações na descrição das características do $A A E$, além de procurar observar algumas das estratégias políticas e ideológicas adotadas na escrita de Morrison com relação às suas escolhas linguísticas.

No que diz respeito a "Tradução, Globalização e Tecnologia", voltado para a formação de tradutores, ele foi bastante prático e informativo. Gentzler buscou ressaltar a tarefa do tradutor em um mundo globalizado, apontando para as diferenças culturais e seus desafios no processo tradutório, o uso de novas tecnologias e o papel do tradutor no mercado de trabalho. Além disso, ele propôs a tradução de textos como currículo, pôster e vídeo, a fim de colocarmos em prática as discussões teóricas realizadas em sala de aula. Por exemplo, para traduzir um currículo, seria relevante que o tradutor considerasse aspectos como o tamanho da fonte, os espaços em branco na página, a pontuação, além de verificar de que forma esse tipo de texto é geralmente formatado na língua de chegada. Há, portanto, uma multiplicidade de fatores envolvidos na atividade de tradução, os quais incluem a produção de um texto que seja funcional para um público-alvo específico. Essa ênfase na funcionalidade da tradução me conduziu a uma reflexão mais profunda sobre as traduções de Beloved e de Jazz no contexto brasileiro, levando em conta determinado conjunto de leitores.

O fato de que o grupo de alunos era formado por pessoas de vários países, tais como Estados Unidos, China, Gabão, Rússia e Polônia, que falam e traduzem para línguas diversas, é um ponto a ser destacado. Durante as aulas, costumávamos discutir algumas peculiaridades linguísticas e culturais e aprendemos muito uns com os outros. Uma ocasião que pode servir de exemplo para esse cenário é a legendagem de filmes na China. Diferentemente do que normalmente ocorre no Brasil, aprendi que as legendas com as traduções em chinês podem ser acompanhadas daquelas com o texto original.

Em "Teoria e Prática de Tradução", Tymoczko forneceu uma grande variedade de leituras na esfera dos Estudos da Tradução. Como sugere o título da disciplina, ela focalizou uma integração da teoria à prática tradutória, levantando discussões e apontando para a complexidade do processo de tradução. $O$ conteúdo programático foi dividido em temas, em vez de seguir uma ordem cronológica de eventos relativos à teoria da tradução. Em suas aulas, nós tínhamos a oportunidade de participar ativamente dos debates sobre pontos relevantes de cada texto teórico, bem como das apresentações dos projetos de tradução.

O primeiro projeto constituiu-se da tradução de uma obra literária ou de outro gênero textual que demonstrasse desafios de ordem linguística, histórica e cultural, que deveria ser acompanhada de uma nota do tradutor. O segundo teve como proposta o desenvolvimento de uma pesquisa sobre diferentes traduções de um mesmo texto ou autor, com o objetivo de ilustrar a história da tradução, mostrar como as estratégias tradutórias estão vinculadas à cultura, aos valores e às ideologias do contexto de 
chegada e constatar como a atividade tradutória sofre alterações ao longo do tempo. Esse projeto em particular mostrou um diálogo muito contundente com o meu estudo e veio a reforçar a visão de que a tradução é moldada de acordo com fatores como o período histórico-cultural e o público leitor.

O grupo de estudantes que fizeram parte desse curso - estadunidenses, argentinos, espanhóis, chineses, iraquianos, entre outros - também é algo a ser destacado. Apesar de as línguas referentes a esses países não serem as mesmas, pudemos observar que temos dificuldades semelhantes ao lidarmos com determinados aspectos tais como humor, religião, comida e variantes linguísticas, em nossa tarefa como tradutores e estudiosos de tradução. Essas ocorrências ficaram bastante evidentes durante as apresentações dos projetos.

Acerca das leituras sugeridas, elas foram muito interessantes para a minha pesquisa, especialmente aquelas pertinentes aos Estudos Descritivos da Tradução (DTS). É importante mencionar que a discussão de textos de teóricos como Itamar Even-Zohar, Gideon Toury, James Holmes e a própria Tymoczko, os quais já são utilizados em minha tese, contribuiu para um pensamento mais abrangente sobre o assunto em questão e será de grande valia para minha abordagem sobre as traduções de Beloved e Jazz no Brasil.

\section{2) Acesso ao centro de tradução}

A possibilidade de trabalhar no centro de tradução também foi significante para o meu estudo. Além de assistir às aulas da disciplina "Tradução, Globalização e Tecnologia", que ocorriam no laboratório de informática, pude aprender de que forma os projetos de tradução são concretizados: a solicitação é feita ao administrador de projetos, o qual busca tradutores filiados ao centro que poderiam realizar determinada tradução e, depois de ser concluída, a mesma é revisada, editada e disponibilizada para o cliente. Nesse ambiente, observei a importância do papel do administrador de projetos, bem como a relevância de um trabalho em equipe. Tive a oportunidade de participar ativamente de dois projetos, como revisora de tradução, a partir dos quais pude verificar que, independentemente do gênero textual em questão, a tradução é um processo complexo que envolve uma atividade minuciosa de pesquisa, revisão e edição.

Um dos projetos consistiu de duas traduções do mesmo material - Guidelines for Preschool Learning Experiences - um guia desenvolvido pela secretaria de educação do estado de Massachusetts, direcionado a professores do ensino pré-escolar. Este livro foi traduzido do inglês para o português brasileiro e para o português europeu, sendo que a primeira tradução serviu de base para a segunda. É importante ressaltar que o público-alvo seria formado por profissionais no âmbito dos Estados Unidos. No que diz respeito à revisão, comecei com o texto em português europeu. Inicialmente pude perceber uma variedade de palavras e expressões que se diferem das que comumente seriam utilizadas no Brasil. Por exemplo, "planning" foi traduzida como "planificação", em vez de "planejamento". Com respeito ao texto em português brasileiro, houve a necessidade de uma revisão mais detalhada, talvez por ele ter sido feito primeiramente. O segundo projeto foi um folder turístico do Plimoth Plantation, um museu histórico localizado em Plymouth, Massachusetts, contendo explicações sobre o navio Mayflower II e traduzido do inglês para o português.

Outro ponto interessante sobre o centro de tradução é que lá está localizado o escritório de Gentzler. Uma vez que ele é o seu diretor, pude encontrá-lo frequentemente e conversar sobre minha pesquisa. Esses momentos foram bastante 
produtivos, pois ele costumava indicar pessoas que eu deveria contactar, leituras que poderia fazer e aspectos sobre os quais seria importante refletir. Um deles trata das especificidades da literatura de Morrison, que vão muito além da linguagem, o que me levou a repensar o modo como venho abordando esse tópico em meu estudo, dando destaque apenas ao inglês afro-americano. Por essa razão, pretendo acrescentar mais características relativas à escrita de Morrison.

\section{3) Visita à biblioteca}

A University of Massachusetts Amherst tem quatro bibliotecas, sendo que a principal - W. E. B. Du Bois - de vinte e seis andares, possui um acervo grandioso e variado. Trata-se de um ambiente bastante funcional, com espaços separados para a utilização de computadores, impressoras e scanners, o estudo em grupo e o estudo individualizado. Seu site www.library.umass.edu reúne uma multiplicidade de materiais de bibliotecas do mundo inteiro, incluindo livros, artigos, periódicos, dissertações e teses, e tem sido uma ferramenta muito importante para o acréscimo de fontes bibliográficas à minha pesquisa.

Um dos bancos de dados presentes no referido site é o Index Translationum: um projeto das Nações Unidas que disponibiliza informações sobre livros traduzidos mundialmente. Com relação às obras de Morrison, por exemplo, pude constatar a existência de 359 registros. Essa lista extensa mostra o quanto os romances de Morrison têm sido traduzidos para várias línguas, tais como o português, o espanhol, o francês e o alemão. O mesmo não acontece com outros gêneros escritos pela autora. Por exemplo, embora ela tenha publicado cinco livros infantis, apenas dois deles foram traduzidos até o momento, somente para o francês e o alemão. Outro fato interessante sobre esse banco de dados é que há informações não só sobre as línguas para as quais os textos foram traduzidos, como também sobre os países em que eles foram lançados. Isso me levou a observar, por exemplo, que a tradução de Beloved realizada por Evelyn Kay Massaro foi publicada tanto no Brasil, quanto em Portugal no ano de 1989.

Outras fontes bibliográficas a que tive acesso até o momento, incluindo capítulos de livros, artigos, dissertações e teses, também serão bastante úteis. Segue uma lista com títulos divididos por assuntos:

Estudos da Tradução

BERTHELE, Raphael. Translating African-American Vernacular English into German: The Problem of 'Jim' in Mark Twain's Huckleberry Finn. Journal of Sociolinguistics, v. 4, n. 4, p. 588-613, 2000.

FEITOSA, Lilian. Brazilian Women Writers in English: Translation of Culture and Gender in Works by Clarice Lispector, Carolina Maria de Jesus, and Ana Maria Machado. Amherst, Massachusetts, 2008. Tese (Doutorado em Literatura Comparada). Programa de Pós-Graduação em Literatura Comparada, UMass Amherst. 490p.

GRAAF, Patty de. African American Identity and Translation Challenges in Toni Morrison's Jazz. Utrecht, Holanda, 2012. Dissertação (Mestrado em Estudos da Tradução). Programa de Pós-Graduação em Estudos da Tradução, Utrecht University. 90p. 
HAUGLUND, Silje Andrea T. Achieving Equivalent Effect in Translation of African American Vernacular English: Foreignization Versus Domestication. Oslo, Noruega, 2011. Dissertação (Mestrado em Estudos da Tradução). Programa de Pós-Graduação em Estudos da Tradução, University of Oslo. 166p.

KRAAI, Marianne. From the Black Margins to the Multi-colored Center: A Search for Patterns in the Manner of Representation of African-American Vernacular English in Dutch Translations of Literature Between the 1980's and the Present. Utrecht, Holanda, 2013. Dissertação (Mestrado em Estudos da Tradução). Programa de Pós-Graduação em Estudos da Tradução, Utrecht University. 110p.

OWSLEY, Joshua L. A Translation of the Introduction and Part III of Free Jazz/Black Power. Amherst, Massachusetts, 2013. Dissertação (Mestrado em Literatura Comparada). Programa de Pós-Graduação em Literatura Comparada, UMass Amherst. $94 \mathrm{p}$.

PRADA-GONZÁLEZ, Lucía. A Translation from English to Spanish of Selected Chapters from Dionne Brand's What We All Long For. Amherst, Massachusetts, 2009. Dissertação (Mestrado em Literatura Comparada). Programa de Pós-Graduação em Literatura Comparada, UMass Amherst. 285p.

SCHWERIN-HIGH, Friederike Von. Translations of The Tempest in Germany and Japan. Amherst, Massachusetts, 2001. Dissertação (Mestrado em Literatura Comparada). Programa de Pós-Graduação em Literatura Comparada, UMass Amherst. 367p.

\section{Toni Morrison e suas obras}

ATKINSON, Yvonne. The Black English Oral Tradition in Beloved: 'Listen to the Spaces'. In: SOLOMON, Barbara H (org.). Critical Essays on Toni Morrison's Beloved. New York: G. K. Hall \& Co.,1998. p. 247-260.

BURTON, Angela. Signifyin(g) Abjection: Narrative Strategies in Toni Morrison's Jazz. In: PEACH, Linda (org.). Toni Morrison. New York: St. Martin's Press, 1998. p. 170-193.

CHRISTIAN, Barbara; MCDOWELL, Deborah e MCKAY, Nellie Y. A Conversation on Toni Morrison's Beloved. In: ANDREWS, William L. e MCKAY, Nellie Y (orgs.). Toni Morrison's Beloved: A Casebook. Oxford: Oxford University Press, 1999. p. 203220.

FRAMPTON, Edith. From the Nobel to Oprah: Toni Morrison, Body Politics, and Oprah's Book Club. In: COTTON, Tristan T. e SPRINGER, Kimberly (orgs.). Stories of Oprah: The Oprahfication of American Culture. Jackson: University Press of Mississippi, 2010. p. 145-159.

MORRISON, Toni. Nobel Lecture 1993. World Literature Today, v. 68, n. 1, p. 5-8, 1994. 
MORRISON, Toni. The Opening Sentences of Beloved. In: SOLOMON, Barbara H. (org.). Critical Essays on Toni Morrison's Beloved. New York: G. K. Hall \& Co.,1998. p. 91-92.

MUELLER, Stefanie. Beloved: Breaking the Back of Words. In: ---. The Presence of The Past in Toni Morrison's Novels. Memmingen: Universitätsverlag Winter GmbH Heidelberg, 2013. p. 211-228.

MUELLER, Stefanie. Epilogue: Toni Morrison and the Literary Field. In: ---. The Presence of The Past in Toni Morrison's Novels. Memmingen: Universitätsverlag Winter GmbH Heidelberg, 2013. p. 229-260.

PÉREZ-TORRES, Rafael. Knitting and Knotting the Narrative Thread: Beloved as Postmodern Novel. Toni Morrison. In: PEACH, Linda (org.). Toni Morrison. New York: St. Martin's Press, 1998. p. 128-139.

RICE, Robert William. Beloved: Narratives of the Self. In: ---. Toni Morrison and the American Tradition: A Rhetorical Reading. New York: Peter Lang, 1996. p. 101-117.

. Introduction. In: ---. Toni Morrison and the American Tradition: A Rhetorical Reading. New York: Peter Lang, 1996. p. 1-17.

. Jazz: Seeking the Name of the Sound. In: ---. Toni Morrison and the American Tradition: A Rhetorical Reading. New York: Peter Lang, 1996. p. 119-137.

RIGNEY, Barbara Hill. Breaking the Back of Words: Language and Signification. In: --. The Voices of Toni Morrison. Chelsea: Ohio State University Press, 1991. p. 7-34.

Breaking the Back of Words: Language, Silence, and the Politics of Identity on Beloved. In: SOLOMON, Barbara H. (org.). Critical Essays on Toni Morrison's Beloved. New York: G. K. Hall \& Co.,1998. p. 138-147.

RODRIGUES, Eusebio L. Experiencing Jazz. In: PEACH, Linda (org.). Toni Morrison. New York: St. Martin's Press, 1998. p. 154-169.

. The Telling of Beloved. In: SOLOMON, Barbara H. (org.). Critical Essays on Toni Morrison's Beloved. New York: G. K. Hall \& Co.,1998. p. 148-165.

RUSHDY, Ashraf H. A. Daughters Signifyin(g) History: The Example of Toni Morrison's Beloved. In: PEACH, Linda (org.). Toni Morrison. New York: St. Martin's Press, 1998. p. 140-153.

SALE, Maggie. Call and Response as Critical Method: African-American Oral Traditions and Beloved. In: SOLOMON, Barbara H. (org.). Critical Essays on Toni Morrison's Beloved. New York: G. K. Hall \& Co.,1998. p. 177-188.

WILlIAMS, Lisa. Beloved. In: ---. The Artist as Outsider in the Novels of Toni Morrison and Virginia Woolf. Westport: Greenwood Press, 2000. p. 151-168. 
Introduction. In: ---. The Artist as Outsider in the Novels of Toni Morrison and Virginia Woolf. Westport: Greenwood Press, 2000. p. 1-22.

Literatura afro-brasileira

ALVES, Miriam. Enfim...Nós: Por quê? In: --- e DURHAM, Carolyn (org.). Enfim Nós: Escritoras Negras Brasileiras Contemporâneas / Finally Us: Contemporary Black Brazilian Black Writers. Colorado Springs: Three Continents Press, 1995. p. 5-15.

DUARTE, Eduardo de Assis. Entre Orfeu e Exu, a Afrodescendência Toma a Palavra. In: ---. Literatura e Afrodescendência no Brasil: Antologia Crítica (Volume 1 Precursores). Belo Horizonte: Editora UFMG, 2011. p. 14-48.

FRANCO, Jean. Introduction. In: SZOKA, Elzbieta (org.). Fourteen Female Voices from Brazil: Interviews and Works.Austin: Host Publications, 2002. p. 5-12.

STERLING, Cheryl. Black Arts Movements e Quilombhoje. In: AFOLABI, Niyi; BARBOSA, Márcio e RIBEIRO, Esmeralda (orgs.). Cadernos Negros: Literatura AfroBrasileira Contemporânea/ Black Notebooks: Contemporary Afro-Brazilian Literature. Trenton: Africa World Press, 2008. p. 201-225.

SZOKA, Elzbieta. Interview With Conceição Evaristo. In: SZOKA, Elzbieta (org.). Fourteen Female Voices from Brazil: Interviews and Works.Austin: Host Publications, 2002. p. 267-272.

SZOKA, Elzbieta. Interview With Esmeralda Ribeiro. In: SZOKA, Elzbieta (org.). Fourteen Female Voices from Brazil: Interviews and Works.Austin: Host Publications, 2002. P. 238-244.

SZOKA, Elzbieta. Interview With Miriam Alves. In: SZOKA, Elzbieta (org.). Fourteen Female Voices from Brazil: Interviews and Works.Austin: Host Publications, 2002. p. 253-260.

Bancos de dados

Index Translationum: para pesquisar informações sobre as traduções da literatura de Morrison.

Newspapers: para verificar a recepção da produção literária de Morrison nos Estados Unidos e em outros países.

Além disso, optei por adquirir estes livros, relativos a diferentes áreas de estudos:

Estudos da Tradução

BASSNETT, Susan e LEFEVERE, Andre (orgs.). Translation, History, and Culture. London: Pinter, 1998.

BASSNETT, Susan. Reflections on Translation. Bristol: Multilingual Matters, 2011. 
DINGWANEY, Anuradha e MAIER, Carol (orgs.). Between Languages and Cultures: Translation and Crosscultural Texts. Pittsburgh: University of Pittsburgh Press, 1994.

TYMOCZKO, Maria e GENTZLER, Edwin. Translation and Power. Amherst: University of Massachusetts Press, 2002.

TYMOCZKO, Maria (org.). Translation, Resistance, Activism. Amherst: University of Massachusetts Press, 2010.

. Enlarging Translation, Empowering Translators. Manchester: St. Jerome,

2007.

. Translation in a Postcolonial Context: Early Irish Literature in English

Translation. Manchester: St. Jerome, 1999.

$\underline{\text { Toni Morrison e suas obras }}$

BEAULIEU, Elizabeth A (org.). The Toni Morrison Encyclopedia. Westport: Greenwood Press, 2003.

CONNER, Marc C. (org.). The Aesthetics of Toni Morrison: Speaking the Unspeakable. Jackson: University Press of Mississippi, 2000.

CHRISTIANSË, Yvette. Toni Morrison: An Ethical Poetics. New York: Fordham University Press, 2013.

DENARD, Carolyn C. (org.). Toni Morrison: Conversations. Jackson: University Press of Mississippi, 2008.

PLAZA, Carl (org.). Toni Morrison: Beloved. New York: Columbia University Press, 1998.

TALLY, Justine. The Story of Jazz: Toni Morrison's Dialogic Imagination. Hamburg: LitVerlag, 2001.

\section{Literatura afro-americana}

BELL, Bernard W. Bearing Witness to African American Literature: Validating and Valorizing Its Authority, Authenticity, and Agency. Detroit: Wayne State University Press, 2012.

LUBIANO, Wahneema. The House That Race Built: Original Essays by Toni Morrison, Angela Y. Davis, Cornel West, and Others on Black Americans and Politics in America Today. Wayne State University Press, 2012.

MINNICK, Lisa Cohen. Dialect and Dichotomy: Literary Representations of African American Speech. Tuscaloosa: University of Alabama, 2004. 
NAPIER, Winston (org.). African American Literary Theory: A Reader. New York: New York University Press, 2000.

QUASHIE, Kevin Everod; LAUSCH, Joyce e MILLER, Keith D. (orgs.). New Bones: Contemporary Black Writers in America. Upper Saddle: Prentice Hall, 2001.

\section{4) Participação em eventos}

O fato de a University of Massachusetts Amherst estar em uma região que permite fácil acesso a outros locais que poderiam ser interessantes para a minha pesquisa é mais um ponto a ser ressaltado. Desde o início do meu estágio, pude participar de importantes eventos relacionados à tradução e à cultura afro-americana.

Em 20 de setembro, ocorreu o simpósio "Cultural Translation", promovido pela Nida School of Translation Studies, no College Board, em Nova York. O formato desse evento foi algo que me chamou a atenção, por ter sido dinâmico e possibilitado a troca de ideias entre os estudiosos. Somam-se a isso os períodos reservados para perguntas e respostas, que permitiram a interação entre os palestrantes e os ouvintes.

Ele foi dividido em dois momentos. No primeiro, Robert Young, professor do departamento de literatura comparada da New York University, teve sua apresentação em diálogo com a de Christi Merrill, professora de literatura do sul asiático e teoria póscolonial na University of Michigan. Young iniciou sua fala enfatizando a tradução como um ato de intervenção cultural. Ele também discutiu a forma como as culturas são transportadas e interpretadas por meio da tradução. Merrill respondeu à sua comunicaão destacando, entre várias questões, a relação entre Sigmund Freud e o campo da tradução. Na segunda sessão, Bella Brodzki, professora de estudos comparativos e internacionais no Sarah Lawrence College, abordou a tradução cultural citando diferentes exemplos para ilustrar o assunto. Um deles se relaciona à escritora caribenha Maryse Condé. Ao ser questionada sobre as traduções de suas obras do francês para outras línguas, ela afirmou que seus livros são intraduzíveis. Esse episódio me levou a pensar sobre qual seria a visão de Morrison acerca da publicação de sua literatura em outros países, assunto que voltará a ser abordado no item 2.6. Suzanne Levine, coordenadora do departamento de Estudos da Tradução da University of California, retomou alguns pontos citados por Brodzki e, como tradutora experiente, argumentou que a tradução é sempre possível, uma vez que se trata de uma nova versão do texto original.

No dia 26 de setembro, foi realizado o colóquio "A Change of Tongue: Questions of Translation in South African Writing", na University of Massachusetts Amherst. Leon de Kock, professor de inglês na Stellenbosch University, África do Sul, e tradutor de livros originalmente escritos em africâner, discursou sobre os desafios pertinentes ao processo de tradução. Ele citou o romance Triomf, de Marlene van Niekerk, marcado por uma linguagem que mistura inglês, africâner e alguns crioulos sul-africanos. Kock o traduziu para o inglês em duas diferentes versões - uma publicada na África do Sul e outra voltada para o mercado editorial internacional - e falou sobre suas escolhas tradutórias, as quais buscaram valorizar o estilo do texto-fonte.

De 10 de setembro a 08 de dezembro, o museu de arte contemporânea da University of Massachusetts Amherst promoveu uma série de eventos sobre o tema "W. E. B. Du Bois in Our Time", em homenagem aos cinquenta anos da morte de W. E. B. Du Bois. Considerado um dos mais renomados intelectuais e ativistas políticos do movimento pelos direitos civis dos negros nos Estados Unidos, seu legado foi discutido por historiadores, cientistas sociais, escritores, entre outros. 
Houve uma exibição contendo obras de dez pintores e artistas plásticos reconhecidos internacionalmente, os quais procuraram oferecer uma contribuição estética ao tributo a Du Bois. Foi uma experiência muito interessante apreciar a variedade de fotos, painéis e esculturas desvelando questões relativas à cultura afro-americana e valorizando a importância de Du Bois para a história mundial.

Também pude participar de um simpósio no dia 28 de setembro, que reuniu pesquisadores de diferentes áreas, tornando-o muito informativo e dinâmico. Ele foi dividido nas seguintes partes - "O homem literário"; "Arte e política"; "UMass e Du Bois"; "Perspectiva racial" e "Legado global" - que incluíram um debate entre três intelectuais, moderado por um professor da University of Massachusetts Amherst e seguido por uma sessão de perguntas e respostas.

Além disso, fui a uma visita guiada a Great Barrington, cidade no estado de Massachusetts em que Du Bois morou parte de sua vida. Os professores David Glassberg (Departamento de História) e Whitney Battle-Baptiste (Departamento de Antropologia) forneceram explicações sobre alguns locais importantes e entregaram apostilas contendo textos de Du Bois, tais como aquele em que descreve a casa em que viveu na cidade em questão e parte de sua autobiografia.

No dia 08 de outubro, Corine Tachtiris, pós-doutoranda em tradução no Hampshire College, em Amherst, apresentou a comunicação "Not Kundera's Sister's: Shifting Discourse Paradigms in and Through Translation". Tachtiris discutiu o trabalho de tradutores e editores na publicação da escrita tcheca em inglês no formato de antologias, especialmente no que diz respeito à literatura produzida por mulheres. Ela mostrou algumas passagens de textos traduzidos da autora Alexandra Berková para confirmar a ideia de que, apesar de escritoras como ela não serem geralmente consideradas feministas em seu país, elas são representadas como tal no contexto de língua inglesa, por meio da tradução. Esse foi um ponto importante para refletir sobre o papel da tradução como formadora de imagens de um autor e de uma obra, assunto que também trago à discussão em minha tese.

Em 06 de novembro, participei do evento "Conversation and Song: Walking the Laureate Road", na Drexel University, em Philadelphia, no estado da Pennsylvania. Nele, apresentaram-se as escritoras Sonia Sanchez, Rita Dove e Toni Morrison e a cantora de jazz Ruth Naomi Floyd. Sanchez fazia perguntas às suas duas colegas de profissão, as quais chama de "sisters", de um modo informal e interativo com o público. Elas conversaram sobre vários tópicos, incluindo seus estilos literários, racismo e feminismo.

Entre as questões de Sanchez para Morrison, estava esta: "O que você gostaria de dizer quando começou a escrever?". E Morrison respondeu com as seguintes palavras: "Inicialmente, o primeiro gesto foi o de escrever um livro que gostaria de ler". Ela explicou que esse objetivo surgiu quando ela começou a refletir sobre questões raciais no contexto da década de 1960, período significativo para a luta dos negros pelos direitos civis nos Estados Unidos. Seu primeiro romance - The Bluest Eye - focalizando a vida de Pecola Breedlove, jovem, mulher e negra, foi publicado em 1970. Morrison afirmou que, no auge do Black Arts Movement e da busca pela valorização do negro através de lemas como "Black is beautiful", as características do personagem mencionado representam o grupo mais vulnerável em uma sociedade predominantemente racista. Nesse livro, Morrison procurou desenvolver uma linguagem feminina, exemplificada por uma passagem em que descreve o estupro de Pecola pelo próprio pai.

Morrison também enfatizou a participação do leitor, com suas experiências e emoções, na construção do sentido em suas obras. Para ilustrar tal ideia, ela citou a primeira frase 
de Paradise (1998): "Elas mataram a garota branca primeiro". Essa estratégia narrativa foi inspirada na prática de "call and response", interação verbal e não-verbal entre emissor e receptor, de origem africana, muito comum no contexto da cultura afroamericana, especialmente em ambientes religiosos. Outro aspecto que Morrison comentou sobre sua escrita é o uso de apelidos, em vez de nomes próprios, para os seus personagens, já que, em suas palavras, "de todos os negros que conheci, nunca soube os seus nomes".

Esse evento foi muito relevante para a minha pesquisa. Pude verificar a importância dessas três escritoras para o âmbito da literatura afro-americana e para um contexto mais amplo, tanto nacional, quanto internacional. A participação do público foi bem atuante e a sessão de perguntas e respostas ao final se revelou como um acréscimo interessante à discussão.

\section{5) Encontros com acadêmicos}

O objetivo dessa atividade foi o de conversar sobre o meu estudo com pesquisadores da University of Massachusetts Amherst e de outras instituições, como o Mount Hoyloke College, situado na cidade de Hadley, Massachusetts. Desde o primeiro encontro, percebi o grande valor desse tipo de interação, uma vez que passei a refletir mais sobre minha pesquisa, acrescentando-lhe novas ideias. Nos parágrafos a seguir, pretendo descrever o perfil desses acadêmicos e algumas de suas contribuições para o desenvolvimento da minha tese.

Lisa Green é professora da área de Linguística, com foco na sintaxe e na semântica do inglês afro-americano. Conversamos sobre algumas semelhanças e diferenças sobre a questão de ser negro nos Estados Unidos e no Brasil, relacionadas a aspectos sociais, históricos e econômicos. Nesse contexto, comparamos a existência de um dialeto utilizado por parte dos negros estadunidenses com a ausência de uma variedade linguística relacionada a raça no contexto brasileiro. Green recomendou a leitura de um capítulo de The Structure and Status of Pidgins and Creoles, de Arthur Spears e Donald Winford, em que é realizado um estudo sobre uma variante linguística afro-brasileira falada em Helvecia, comunidade quilombola situada na Bahia.

Thomas Roeper está vinculado ao mesmo campo de estudos, focalizando abordagens teóricas sobre aquisição de linguagem e morfologia. De 1998 a 2004, ele foi um dos principais colaboradores em um estudo sobre discurso e padrões linguísticos em crianças afro-americanas. Ele sugeriu textos literários de autores negros como Richard Wright e John Wideman e destacou como o uso do $A A E$ pode gerar reações preconceituosas contra seus falantes. Esse comentário me levou a pensar sobre a complexidade de se traduzir essa variante linguística para o português, tendo em vista a possibilidade de estigmatização dos personagens negros a partir de determinadas escolhas vocabulares.

Laura Doyle é afiliada ao departamento de Inglês, tendo ministrado cursos sobre modernismos globais, história do romance, estudos pós-coloniais, entre outros. Ela mencionou uma série de seminários promovidos pela universidade, em parceria com outras instituições de ensino da região, para compartilhar ideias em determinadas áreas de interesse. Além disso, passei a ser informada dos eventos que aconteceriam no período do meu estágio. Discutimos questões raciais nos Estados Unidos e no Brasil e ela sugeriu o livro Cannibal Democracy: Race and Representation in the Literature of the Americas, de Zita Nunes, em que são abordadas obras de autores como Gilberto Freire, Mario de Andrade, Du Bois e Morrison. 
Emily Lordi também está no departamento de Inglês e oferece cursos sobre literatura afro-americana e cultura popular negra. Tivemos uma conversa interessante sobre a imagem de Morrison nos Estados Unidos. Por exemplo, Lordi destacou o fato de que, nos anos de 1970, a autora deixou em segundo plano sua carreira como editora e passou a se concentrar na produção de suas próprias obras. Além disso, ela enfatizou o papel desempenhado pela apresentadora Oprah Winfrey na divulgação dos romances de Morrison para um público mais generalizado. Entre suas recomendações de leitura estão as entrevistas, o ensaio "Unspeakable Things Unspoken: The Afro-American Presence in American Literature" e o livro Playing in the Dark: Whiteness and the Literary Imagination, de Morrison, assim como os capítulos 5 e 6 de The Signifying Monkey: A Theory of African American Literary Criticism, em que Henry Louis Gates Jr. desenvolve um estudo sobre a linguagem na literatura afro-americana.

Flavia Santos de Araújo é doutoranda no departamento de Estudos Afro-Americanos. Sua tese é um estudo comparativo entre as escritoras afro-brasileiras Conceição Evaristo e Miriam Alves e as afro-americanas Audre Lorde, June Jordan e Gayl Jones, com destaque para questões de gênero e raça. Conversamos sobre as literaturas afroamericana e afro-brasileira e suas possíveis correlações e ela me relatou um episódio interessante do qual não tinha conhecimento. Morrison veio ao Brasil na década de 1990, após ser convidada pela editora que publicava seus livros naquela época em nosso país. Ao chegar aqui, ela indagou ao seu editor sobre o trabalho de autores negros. Diante disso, acabou sendo promovido um encontro entre ela e alguns dos membros do Quilombhoje, grupo formado por ativistas negros em São Paulo, criado nos anos de 1980. Uma foto relativa a tal encontro está presente em Cadernos Negros: Três Décadas - Ensaios, Poemas, Contos (2008), organizado por Esmeralda Ribeiro e Márcio Barbosa. Araújo e eu também comentamos sobre a invisibilidade da literatura afro-brasileira em nosso país e a importância de vozes como as nossas na colaboração para uma mudança nesse cenário desvantajoso. Além disso, ela compartilhou materiais de leitura que serão relevantes para a minha pesquisa.

James Smethurst é orientador de Araújo e professor no departamento de Estudos AfroAmericanos. Seus interesses acadêmicos incluem literatura e cultura afro-americanas, principalmente no que tange ao período do Black Arts Movement no sul dos Estados Unidos. Durante nossa reunião, ele levantou vários pontos sobre Morrison e sua controversa literatura: apesar de sua escrita ser geralmente considerada complexa e de difícil compreensão, seus livros vendem bem. Com relação a Beloved, ele ponderou sobre o tema da escravidão e o realismo mágico frequentemente associados ao romance. Também nos referimos à polêmica em torno do livro, já que ele é valorizado no meio acadêmico, mas banido em escolas de ensino médio. Acerca de Jazz, a ausência de elementos sobrenaturais pode ser um dos motivos sobre os quais ele não tão comentado pela crítica. Segundo Smethurst, seria importante que eu averiguasse a recepção de Morrison e de suas obras tanto em fontes relativas à cultura afro-americana, quanto naquelas voltadas para a literatura em geral, de forma a observar que aspectos são destacados e quais deles são silenciados.

Maria Tymoczko, reconhecida estudiosa do campo da tradução, é afiliada ao departamento de Línguas, Literaturas e Culturas. Após o encerramento de seu curso, tive a oportunidade de encontrá-la e falar sobre a minha pesquisa mais detalhadamente. Ela fez várias recomendações, entre as quais podem ser citadas a ampliação do estudo sobre Morrison, incorporando discussões que vão além do contexto afro-americano, e a análise das traduções sob um viés mais político e ideológico, em vez de focalizar apenas questões linguísticas pontuais. Quanto às sugestões de leitura, soma-se àquelas 
realizadas durante suas aulas, o artigo "What are Descriptive Studies into Translation Likely to Yield Apart From Isolated Descriptions?" (1991), de Gideon Toury.

Carolyn Shread é professora de francês no Mount Holyoke College, além de tradutora experiente. Sua pesquisa trata da literatura francófona sob a perspectiva dos Estudos da Tradução. Durante nosso encontro, ela levantou algumas questões sobre o meu estudo tais como "Qual o propósito de se traduzir Morrison no Brasil?"; "Por que seus livros infantis ainda não estão disponíveis em português?" e "Quem está legitimando as obras de Morrison no contexto de recepção?". Além disso, ela indicou a leitura de The Politics of Translation, de Gayatri Spivak, e Packaging Post/Colonialty: The Manufacture of Literary Identity in the Francophone World, de Richards Watts.

\section{6) Contatos relativos a Morrison}

Após longo período buscando maneiras de estabelecer contato com Morrison, consegui ter acesso ao e-mail de sua assistente e escrevi para ela. Ela foi bastante receptiva e concordou que eu lhe mandasse algumas perguntas, mesmo que não houvesse a garantia de que a autora irá respondê-las. Diante desse quadro, enviei-lhe uma carta apresentando meu estudo e sugerindo questões sobre a tradução de sua literatura.

No que diz respeito à agente literária que lida com os direitos de tradução dos livros de Morrison, cheguei à informação de que se trata de Helen Manders, da Curtis Brown. O site da empresa apresenta dados interessantes sobre o assunto em questão: http://www.curtisbrown.co.uk/toni-morrison/.

Embora tenha entrado em contato com a secretária de Manders, ela sugeriu que lhe enviasse outro e-mail futuramente, devido à alta demanda de trabalho naquele período. Nesse caso, preparei algumas perguntas que vejo como acréscimos importantes ao meu estudo.

\section{3) Considerações finais}

O estágio na University of Massachusetts Amherst foi muito importante para o aprimoramento da minha tese. Apesar do curto período de tempo, aprendi bastante e acredito que estou mais madura intelectualmente para dar prosseguimento ao meu estudo. Ainda há muitas reflexões a serem feitas, entretanto já consigo visualizar algumas ideias de mudanças e acréscimos.

Essa oportunidade de estudo promovida pela CAPES por meio da bolsa PDSE é de fundamental relevância para qualquer pesquisador, já que ela conduz a um amadurecimento intelectual, acadêmico e, sobretudo, cultural. Espero que seja capaz de utilizar todo o conhecimento adquirido nesse período e tenha sucesso na conclusão da minha tese e na obtenção do meu título de doutorado. Por fim, gostaria de agradecer aos meus orientadores Marcia do Amaral Peixoto Martins e Edwin Gentzler, à CAPES e à PUC-Rio, que apoiaram o meu trabalho e contribuíram para o desenvolvimento do meu projeto de pesquisa no exterior. 